\title{
Novel Neuroprotective Formulations Based on St. John's Wort Extract
}

\author{
Monica Vazzana ${ }^{1,2}$, Ana S. Macedo ${ }^{2}$, Antonello Santini ${ }^{3}$, Caterina Faggio ${ }^{1}$ \& Eliana B. Souto ${ }^{2,4}$ \\ ${ }^{1}$ Department of Biological and Environmental Sciences, University of Messina, Viale Fernando Stagno d' \\ Alcontres, 31, 98166 S. Agata- Messina, Italy \\ ${ }^{2}$ Faculty of Health Sciences, Fernando Pessoa University (FCS-UFP), Rua Carlos da Maia, 296, P-4200-150 \\ Porto, Portugal \\ ${ }^{3}$ Department of Pharmacy, University of Napoli “Federico II", Via D. Montesano 49, 80131 Napoli, Italy \\ ${ }^{4}$ Institute of Biotechnology and Bioengineering, Centre of Genetics and Biotechnology, University of \\ Trás-os-Montes and Alto Douro (IBB/CGB-UTAD), P-5000-801 Vila Real, Portugal \\ Correspondence: Eliana B. Souto, Faculty of Health Sciences of Fernando Pessoa University, Rua Carlos da \\ Maia, 296, Office S.1, P-4200-150 Porto, Portugal. Tel: 351-22-507-4630. E-mail: eliana@ufp.edu.pt
}

Received: June 10, 2013 Accepted: December 10, 2013 Online Published: April 10, 2014

doi:10.5539/jfr.v3n4p3 URL: http://dx.doi.org/10.5539/jfr.v3n4p3

\begin{abstract}
St. John's Wort (SJW) has been intensively studied in the last years with respect to its pharmacological properties and to understand the mechanism of action of its bioactive compounds. In fact, it is currently used for the treatment of several disorders. Nevertheless, only recently nanotechnology has been applied for the delivery of SJW extract in vivo, to enhance its neuroprotective properties. In the present review, the advantages, the chemical characterization and the special biological features of SJW extract are discussed, underlining the potential use of nanotechnology in the development of drug carrier systems based on lipid nanoparticles. A special focus is given to solid lipid nanoparticles (SLN) and to nanostructured lipid carriers (NLC) given their versatility for a wide range of bioactive compounds.
\end{abstract}

Keywords: hypericum perforatum, SLN, NLC, biological effects, chemical properties, bioactive compounds

\section{Introduction}

St. John's Wort (SJW), scientifically called Hypericum perforatum (Hypericaceae), is a herbaceous medicinal perennial plant, known for its antiviral, antibacterial (Gram+), antitumoral, antiangiogenic and antiinflammatory properties. It is currently used in the treatment of mild to moderately severe forms of depression, alcoholism or as topical remedy for wounds, abrasion, burns and muscle pain, thanks to its antiseptic and cicatrizant properties (Caccia \& Gobbi, 2009; Saddiqe et al., 2010; Meinke et al., 2012; Leuner et al., 2013). However, adverse side effects are photosensitivity (Onoue et al., 2011) and physical-chemical interaction between plant extract and drugs that can result in the formation of microparticles, nanoparticles and precipitates (Gröning et al., 2003; Müller et al., 2004). Indeed, it is well-known that the extracts of SJW affect the metabolism of e.g. the Human Immunodeficiency Virus-1 (HIV-1) protease inhibitor indinavir, the immunosuppressant cyclosporin, the cardiotonic digoxin, the anticoagulant warfarin and oral contraceptives. These interactions are suggested to be due to the effects of SJW extract in inducing the intestinal P-glycoprotein drug transporter and in inducing a drug-metabolizing enzyme: cytochrome P-3A4 (CYP3A4), isoenzyme of Cytochrome P-450 (Ott et al., 2010). SJW has been intensively studied on isolated tissue samples, using animal models and also in human clinical trials (Klemow et al., 2011). 
Table 1. Composition of St. John's Wort extract

\begin{tabular}{|c|c|c|c|}
\hline CLASSES & $\begin{array}{c}\text { CONTENT } \\
\% *\end{array}$ & CONSTITUENTS & $\begin{array}{c}\text { CONTENT } \\
\% *\end{array}$ \\
\hline \multirow{3}{*}{ NAPHTHODIANTHRONES } & \multirow{3}{*}{$0.1-0.6 \%$} & Hypericin & $0.03-0.3 \%$ \\
\hline & & $\begin{array}{l}\text { Isohypericin, Protohypericin, } \\
\text { Pseudoprotohypericin }\end{array}$ & \\
\hline & & Pseudohypericin & \\
\hline \multirow{2}{*}{ FLAVONOIDS } & \multirow{2}{*}{$7-12 \%$} & $\begin{array}{c}\text { Kaempferol, Luteolin, Myricetin, } \\
\text { Quercitrin, Hyperoside, }\end{array}$ & \\
\hline & & Rutin, Quercetin, I3,II8-biapigenin & \\
\hline \multirow{2}{*}{ ACYLPHLOROGLUCINOLS } & & Hyperforin & $2-4.5 \%$ \\
\hline & & Adhyperforin & $0.2-1.9 \%$ \\
\hline
\end{tabular}

Terpenoids: $\alpha$-pinene, monoterpenes,

ESSENTIAL OIL $\quad 0.05-0.9 \% \quad$ sesquiterpenes

Aliphatic coumponds

PHENILPROPANES

PROANTHOCYANIDINS
Caffeic acid, p-coumaric acid, Ferulic acid, Chlorogenic acid

Acids, Carotenoids, Amino acids,
Nicotinamide, Vitamin C

*Content of each constituent in hydroalcoholic extracts (ethanol or methanol) of aerial parts of the plant.

Table 1 shows the chemical composition of the SJW extract by linking the main classes and respective constituents with their percentage content.

Among different methods to obtain the extract, Khan et al. suggest the cleaning of aerial parts of the plant, the drying in the shade and the coarsely grounding (Khan et al., 2011). Then, the powdered material is extracted with $70 \%$ aqueous ethanol by cold maceration for three days with occasional shaking. After that, the stuff is filtered and finally, the combined filtrate is evaporated in a rotary evaporator under reduced pressure to a thick, semi-solid mass of dark brown color, i.e. crude extract of Hypericum perforatum, yielding approximately $18.52 \% \mathrm{w} / \mathrm{w}$ (Khan et al., 2011). Nevertheless, it is now possible to find and buy commercial samples ready to use. Isacchi et al. have shown that a commercial sample of dried extract contains $12.7 \%$ flavonoids, $4.2 \%$ hyperforin, $0.3 \%$ hypericin. The authors have also reported the sample solubility i.e. $353 \mu \mathrm{g} / \mathrm{ml}$ for flavonoids, $6.9 \mu \mathrm{g} / \mathrm{ml}$ for I3, II8-biapigenin, $<0.1 \% \mu \mathrm{g} / \mathrm{ml}$ for hyperforin and $10.4 \mu \mathrm{g} / \mathrm{ml}$ for hypericin (Isacchi et al., 2009). However, among all, only two substances, hyperforin and hypericin, are reported to have the greatest medical and therapeutic activities.

\subsection{Hyperforin Is a Multipotent Agent}

Hyperforin is the major lipophilic constituent of SJW flowers and leaves, but it is unstable and its lability to oxidative degradation leads to changes in the composition of the extracts. A successful method for its isolation, purification and storing, allowing handling quantities of compound, has been developed (Verotta, 2003). A series of counter extractions of the $\mathrm{CO}_{2}$ extract provides a residue, which is finally partitioned in petrol/acetonitrile/MeOH, and both phases are submitted to high speed countercurrent chromatography. Hyperforin and adhyperforin are quantitatively separated and isolated as last eluted compounds. Due to their lability to air and light, they should be preserved in methanol solutions at $-20{ }^{\circ} \mathrm{C}$ or immediately used for biological evaluation. In order to preserve the phloroglucinols in a stable form, easily-handled for biological studies, they can be derivatized as organic or inorganic salts, or separated and isolated through a counter current chromatography of their correspondent dicyclohexylamonium salts. Final purification of the components is achieved by silica gel chromatography (Verotta, 2003).

The available data suggest that hyperforin is the most likely candidate to explain the antidepressant effect of 
hydroalcoholic SJW extracts (Cervo et al., 2002). In several animal studies, hyperforin has shown antidepressant activity, and the potency of SJW is correlated to the content of hyperforin (Cervo et al., 2002; Caccia \& Gobbi, 2009). Previous studies indicated that hyperforin, similar to antidepressants, enhances monoaminergic neurotransmission by inhibiting the synaptic reuptake of monoamines (Butterweck, 2003). It takes weeks for the mood enhancing effects of antidepressant drugs to be evident in patients, which suggests that neurobiological changes are involved, in addition to monoamine deficiency in depression (Wang et al., 2011).

In vitro experiments showed that hyperforin blocks the uptake of several neurotrasmitters like dopamine, serotonin, noradrenaline and glutamate by increasing the free cytosolic concentration of $\mathrm{Na}^{+}$, whereas in vivo it elevates the extracellular levels of glutamate, dopamine, noradrenaline and serotonine but not of GABA in the brain of rats. The IC50 values (concentration resulting in 50\% inhibition) of approximately $0.05-0.1 \mu \mathrm{g} / \mathrm{mL}$ for neurotransmitters was reported in synaptosomal preparations (Mennini \& Gobbi, 2004). It also influences the cellular homeostasis of $\mathrm{Ca}^{2+}$ through blocking some conducting channels such as voltage-gated $\mathrm{Ca}^{2+}$ and N-metil-D-aspartato (NMDA) receptors (Kumar et al., 2006). Moreover, it can elevate the cytosolic concentration of free $\mathrm{Ca}^{2+}$ by promoting its release from mitochondria up to, acutely applied $(\geq 1 \mu \mathrm{M})$, induce the collapse of their membrane potential, the release of Cytochrome $\mathrm{c}$ and the mobilization of $\mathrm{Ca}^{2+}$ and $\mathrm{Zn}^{2+}(\mathrm{Tu}$ et al., 2010), changing the zinc-storage capacities of brain cells (Gibon et al., 2011).

Hyperforin is a potent activator of a non-selective cationic channel permeable to $\mathrm{Ca}^{2+}$ (TRPC6 channel) expressed in many cell types, including neurons and it plays a critical role in promoting neuronal survival (Kim et al., 2012; Valeri et al., 2012). Through the activation of TRPC6 channels, it modulates dendritic spines, the main loci of synaptic plasticity, density and morphology in hippocampal pyramidal neurons (Leuner et al., 2013). Furthermore, a chronic hyperforin treatment up-regulates the expression of metallothioneins, performing beneficial effects with neuroprotective functions and elevating the brain sulphur content (Gibon et al., 2011).

Hyperforin is also a powerful free radical scavenger with high antioxidant activity. This feature was supported by the production of a cream for skin application with UV-protective effects by Meinke et al (Meinke et al., 2012).

Valeri et al. instead, evaluated the ability of SJW extract to perform neuroprotective activity in rat urinary bladders subjected to anoxia-glucopenia/reperfusion (A-G/R) injury, considering the association between depression and urinary incontinence (Valeri et al., 2012). The authors concluded that SJW, even though showing spasmolytic activity, it has no neuroprotective effect on rat urinary bladder subjected to A-G/R injury. Regarding the effects on contraction, the authors found that both hypericin and hyperforin have a dual effect: at low concentrations they increase the contractile response, whereas at high concentrations they exert relaxing effect, with hypericin being mainly involved in plasma membrane depolarization, while hyperforin is more active in the cholinergic system (Valeri et al., 2012).

Recent studies support the role of myelin and oligodendrocyte (OL) dysfunction in the pathogenesis of major depressive disorder (MDD) (Wang et al., 2011). It is indeed reported that hyperforin enhances the survival of OLs in rat experimental allergic encephalomyelitis model. SJW and hyperforin increase the expression of genes and proteins related to energy metabolism in vitro and elevate energy demand, that is considered a key factor in the process of OLs differentiation and myelination. Wang et al. have found that hyperforin promotes mitochondrial function and development of OLs, preventing mitochondrial toxin-induced cytotoxicity in differentiating OL-like cells. These findings suggest that hyperforin may increase the number of available functioning OLs in the brain of patients with depression, by promoting development, mitochondrial function and survival of OLs (Wang et al., 2011).

The antiinflammatory and anticarcinogenic properties attributed to hyperforin can be ascribed to the inhibition of 5-lipoxygenase and the production of prostaglandine $\mathrm{E}_{2}\left(\mathrm{PGE}_{2}\right)$ (Werz et al., 2011). Hyperforin induces apoptosis of various cancer cells, such as mammary carcinoma, squamous cell carcinoma, malignant melanoma and lymphoma cells. Chronic low-grade inflammation and related neuronal leak are common features of major depression, and the latter in turn represents a frequent prelude to dementia in later life. Following the activation, microglia, the immunocompetent cells in the brain, get highly phagocytic activity and release proinflammatory mediators like nitric oxide (NO). Its excessive production is critical in neurodegenerative disorders and there is evidence that abnormalities in NO production and inflammatory responses may support a range of neuropsychiatric disorders, including depression (Kraus et al., 2010). The results of several studies reveal that hyperforin influences pro-inflammatory and immunological responses of microglia, that are involved in the progression of neuropathologic diseases. This activity is mediated by a suppression of inducible nitric oxide synthase (iNOS) expression on the mRNA and protein level (Kraus et al., 2010).

Galeotti et al. demonstrated the ability of SJW to relieve neuropathic pain in rat models, through hypericin 
mediated inhibition of the protein kinase C (PKC) $\gamma$ and $\varepsilon$ activity and their phosphorylation (Galeotti et al., 2010). Neuropathic pain can arise from a wide variety of damages to peripheral or central nerves, including metabolic disorders, traumatic injury, inflammation and neurotoxicity, and it is characterized by spontaneous pain, hyperalgesia and allodynia which can persist for long time after the initial injury is resolved. Neuropathic pain occurs frequently in cancer as it may result from tumor invasion of nervous tissue, surgical nerve injury during tumor removal, radiation induced nerve damage or as side effect of many chemotherapeutic drugs (Galeotti et al., 2010). The authors showed that a single oral administration of SJW, chloroform and methanol fractions, as well as purified hyperforin and hypericin, relieves neuropathic pain in rats with positive side-effects profile. This increase of the pain threshold is associated to the modulation of two different intracellular pathways. The activation of the opioid system, underlining the presence of hyperforin, which is responsible for the antinociceptive properties, and a PKC-mediated mechanism through the PKC-blocking properties of hypericin, mainly related to the antihyperalgesic activity. In conclusion, these results support the hypothesis that the inhibition of PKC specific isoforms might be a promising strategy for the treatment of neuropathic pain (Galeotti et al., 2010). Thus, daily intake of SJW extract seems to be hopeful for the chronic pain treatment in conditions as e.g. premenstrual syndrome.

NO donors increase expression and phosphorylation of PKC $\gamma$ and $\varepsilon$ isoforms, contributing to the sensitization during inflammatory and neuropathic pain, molecular events prevented by SJW or hypericin. In this respect, SJW represents an important therapeutic perspective for the treatment of nociceptive hypersensitivity (Galeotti \& Ghelardini, 2012).

SJW extract decreases P-glycoprotein, the most significant drug efflux transporter at the blood-brain barrier (BBB), transport activity in a dose and time-dependent manner. Particularly, hyperforin directly inhibits P-glycoprotein-mediated transport (Ott et al., 2010).

Onoue et al. have studied the photochemical properties of SJW extract, with focus on generation of reactive oxygen species (ROS), lipid peroxidation and DNA photocleavage, which are indicative of photosensitive, photoirritant and photogenotoxic potentials, respectively. Their results suggest that hypericin, pseudohypericin and hyperforin might be responsible for the in vitro phototoxic effect of SJW extract. Although, concomitant UV exposure of hyperforin with quercitrin, a potent UV/Vis adsorber, leads to a prominent attenuation of photodynamic generation of singlet of oxygen and in the modulated in vitro photochemical behavior of hyperforin (Onoue et al., 2011).

Finally, hyperforin seems to have also cognitive enhancing, memory facilitating properties and neuroprotective activity against Alzheimer's disease neuropathology, including the ability to disassemble amyloid-B aggregates in vitro and to prevent amyloid-B induced neurotoxicity (Griffith et al., 2010).

\subsection{Features of Hypericin}

Hypericin is an antiviral and antineoplastic agent, commonly used for the treatment of a variety of malignant tumors (Lu \& Atkins 2004). It can be employed in two different medical applications, i.e. as photosensitizer for the photodynamic therapy of cancer by mean its single oxygen production, or it can be used for the photo-diagnosis of early epithelial cancer by taking advantage of its specific accumulation in various types of tumor cells (Kah et al., 2008; Ritz et al., 2008). Among different targets, tumor melanocytes (Hadjur et al., 1996), glioma cells (Huntosova et al., 2012), isolated crayfish neuron (Uzdensky et al., 2003) and hepatocellular carcinoma cells (Fadel et al., 2010) were quoted and reported as cell models for the study of the photodynamic efficacy of hypericin after photoirradiation.

Another feature is its antidepressant action by acting on voltage-dependent $\mathrm{K}^{+}$channels in hippocampal neurons, enhancing presinaptic efficiency (Wang et al., 2010).

Initial in vitro studies on compounds responsible for antidepressant activity of SJW indicated hypericin as an inhibitor of monoamine oxidase (MAO) enzymes. However, the used samples were later proved to be impure, containing at least $20 \%$ of other substances of the extract, such as flavonoids. In fact, the MAO inhibitory effects of hypericin could not be confirmed in subsequent studies (Butterweck, 2003; Silva et al., 2008).

Other recent studies have demonstrated that flavonoids might also be more important for antidepressant activity (Nahrstedt \& Butterweck, 2010). In this respect, Silva et al. have found that flavonoids such as quercetin and kaempferol provide neuroprotective action by decreasing oxidation of the mitochondrial lipid membrane and maintaining mitochondrial transmembrane electric potential (Silva et al., 2008).

Hypericin is very lipophilic and water-insoluble, commonly used to standardize SJW extracts. Due to its hydrophobicity, its systemic administration is problematic thus limiting its medical applications. However, 
different delivery methods have been developed. For instance, Fadel et al. have taken advantage of two delivery techniques namely liposomes and anti-hepatocyte specific antigen (Fadel et al., 2010). Uzdensky et al. have used polyvinylpyrrolidone (PVP) as carrier, producing a water-soluble form of hypericin (Uzdensky et al., 2003). Zeisser-Laboùebe et al. and Youssef et al. have used, respectively, polymeric nanoparticles and solid lipid nanoparticles (SLN) (Zeisser-Labouèbe et al., 2006; Youssef et al., 2012).

\section{SLN and NLC: Colloidal Drug Delivery Systems}

Nanotechnology, in the notably context of drug delivery, can be defined as the technologies for producing nanocarriers of therapeutic and imaging agents (Wang \& Wu, 2012). Among potential candidates, "Solid Lipid Nanoparticles" (SLN) and "Nanostructured Lipid Carriers" (NLC) are here considered.

Lipid nanoparticles are extensively employed as drug delivery systems in the field of pharmaceutical technology, for various applications and routes of administration. They show interesting features concerning therapeutic purposes. During the last ten years, different substances have been entrapped into them, ranging from lipophilic to hydrophilic molecules, including labile compounds, such as proteins and peptides (Almeida \& Souto, 2007; Severino et al., 2012). Another advantage is the fact that their matrix is composed of physiological components and/or excipients of accepted status approved by the Food and Drug Administration (FDA), decreasing the risk of acute and chronic toxicity (Souto \& Muller, 2008; Martins et al., 2012). They are also able to protect the loaded drugs from chemical and enzymatic degradation after oral administration and gradually release them from lipid matrix into blood, leading to improved therapeutic profiles compared to free drug (Severino et al., 2012).

SLN were introduced in 1991 as colloidal drug carriers for oral, parenteral and topical administration (Muller et al., 2000), more recently also for pulmonary, dermal, brain and ocular targeting (Souto et al., 2010; Del Pozo-Rodriguez et al., 2013). They are new pharmaceutical formulations, alternative to emulsions, liposomes and polymeric nanoparticles (Weyhers et al., 2006). These systems offer unique properties, such as small size, large surface area, high drug loading, interaction of phases at the interfaces and they are attractive for the potential to improve the bioavailability and performance of pharmaceuticals, neutraceuticals and other materials, exerting prolonged drug release, specific targeting and reducing adverse side effects (Waghmare, 2012).

SLN have a solid lipid matrix that can solubilize lipophilic molecules and should be solid at both room and body temperatures, ranging from $50 \mathrm{~nm}$ to $1000 \mathrm{~nm}$ in terms of particle size. The concept of lipid is used here in a broader sense and includes triglycerides, diglycerides, monoglycerides, fatty acids, steroids and waxes (Fangueiro et al., 2012). Lipid selection is based on the evaluation of the polymorphic, crystallinity, miscibility, and physicochemical structure (Souto \& Muller, 2010). The lipid matrix is stabilized by surfactants (emulsifiers). In this regard, all classes of emulsifiers (with respect to charge and molecular weight) have been used and it has been found that the combination of different emulsifiers may prevent particle agglomeration more efficiently. In fact, the main task of the surfactant is to stabilize lipid nanoparticles in the colloidal state in order to avoid particle size growth during storage. SLN are produced by replacing the liquid lipid (oil) of an oil in water (o/w) emulsion by a solid lipid or a blend of solid lipids. They can be composed by $0.1 \%-30 \%(\mathrm{w} / \mathrm{w})$ solid lipid dispersed in an aqueous medium and if necessary stabilized with preferably $0.5 \%-5 \%(\mathrm{w} / \mathrm{w})$ surfactant (Pardeike et al., 2009). SLN are biocompatible and biodegradable, they show high loading capacity for a broad range of drugs, and they can be freeze dried to form powdered formulation.

A second generation of lipid nanoparticles is represented by NLC, able to overcome observed failures of ordinary SLN. Compared to SLN, NLC show a higher drug loading capacity, a lower water content of the particle suspension and avoid/minimize potential expulsion of drugs during storage. The main difference between SLN and NLC is based on the concept that NLC are obtained by nanostructuring the lipid matrix in order to increase the drug loading and to prevent its leakage, giving more flexibility for the modulation of drug release (Severino et al., 2012). To obtain the blends for the particles matrix, solid lipids are mixed with liquid lipids (oils), preferably in a ratio of 70:30 up to a ratio of 99.9:0.1 (Pardeike et al., 2009). Due to the oil in these mixtures a melting point depression compared to the pure solid lipid is observed, but the blends obtained are also solid at body temperature. The result is a less-ordered lipid matrix with many imperfections, but suitable to accommodate a higher amount of drug (Xia et al., 2007; Severino et al., 2012).

The use of mono and diglycerides in the lipid matrix composition might increase drug solubility compared to highly pure lipids, such as monoacid triglycerides. Naturally occurring oils and fats are extensively employed in the form of mixtures of mono, di, and triglycerides, containing fatty acids of varying chain length and degree of unsaturation. The melting point of these lipids increases with the length of the fatty acid chain and decreases with the degree of unsaturation. Therefore, the chemical nature of the lipid is very important, since lipids forming highly crystalline particles with a perfect lattice (monoacid triglycerides) lead to drug expulsion during 
storage time. However, physicochemically stable lipid nanoparticles are obtained only when the proper surfactant and adequate concentration are employed (Severino et al., 2012).

The choice of the ideal surfactant for a particular lipid matrix is based on the surfactant properties such as charge, molecular weight, chemical structure and respective hydrophile-lipophile balance (HLB) consisting in the balance between the size and strength of the hydrophilic and the lipophilic groups. In fact, all emulsifiers consist of a molecule that combines both hydrophilic and lipophilic groups. Lipophilic emulsifiers own low HLB values (below 9), hydrophilic emulsifiers high HLB values (above 11), while in the range of 9-11 they are defined intermediate. Thus, the HLB system is a valid method to choose the ideal emulsifier or blend of emulsifiers depending on the type of the system involved, i.e. oil-in-water $(\mathrm{o} / \mathrm{w})$, water-in-oil (w/o) or double (w/o/w) emulsion. Well-matched HLB values allow to obtain suitable in vitro performance of the formulation (Severino et al., 2012).

Many different techniques for the production of lipid nanoparticles have been described in the literature. These methods are high pressure homogenization (HPH), microemulsion technique, emulsification-solvent evaporation, emulsification-solvent diffusion method, solvent injection (or solvent displacement) method, phase inversion, multiple emulsion technique, ultrasonication and membrane contractor technique. However, HPH technique has many advantages compared to the other methods, e.g. easy scale up, avoidance of organic solvents and short production time. High pressure homogenizers are widely used in many industries including the pharmaceutical industry, e.g. for the production of emulsions for parenteral nutrition (Pardeike et al., 2009).

Lipid nanoparticles can be obtained by both the hot or cold HPH technique. The drug is dissolved or dispersed in melted solid lipid for SLN or in a mixture of liquid lipid (oil) and melted solid lipid for NLC (Pardeike et al., 2009). In brief, the hot homogenization technique is performed by: a) dissolving, dispersion or solubilization of the drug in the melted lipids; b) dispersion of the melted lipid containing the drug in a hot aqueous surfactant solution; c) preparation of a pre-emulsion by high-speed stirring of the previous dispersion; d) application of HPH to obtain a hot nanoemulsion; e) solidification by cooling at room temperature to obtain lipid nanoparticles (Del Pozo-Rodriguez et al., 2013).

In the cold homogenization method, the blend containing the drug added to lipid melt is cooled down. Briefly, the process consists in: a) dissolving, dispersion or solubilization of the drug in the melted lipid/lipid blend; b) solidification of the mixture by rapid cooling using liquid nitrogen or dry ice; c) milling of the mixture in order to reduce the size; d) preparation of a pre-suspension by dispersion of the lipid phase in a cold aqueous surfactant solution; e) application of HPH at/below room temperature to obtain lipid nanoparticles. With this technique, the burst effect and the thermal exposure of the drug are reduced, but the particle size and the polydispersity index (PI) are higher compared to the ones in the hot technique (Del Pozo-Rodriguez et al., 2013).

In the case of formulations for topical delivery based on SLN or NLC, these can be obtained by admixing SLN/NLC to existing products, by adding viscosity enhancers to the aqueous phase of SLN/NLC to obtain a gel or through the direct production of a final product containing only nanoparticles in a one-step process (Pardeike et al., 2009).

SLN and NLC have also appropriate features for dermal application of cosmetics and pharmaceutics, i.e. small size, high surface area, controlled release of bioactive molecules, drug targeting, occlusion and associated with it penetration enhancement and increase of skin hydration and elasticity (Pardeike et al., 2009). The enhanced hydration is obtained because nanosized particles are able to form a film on the surface of skin, promoting occlusiveness and reducing skin water evaporation (Severino et al., 2013)

Thanks to the production of lipid nanoparticles from physiological and/or biodegradable lipids, these delivery systems exhibit an excellent tolerability and they are "nanosafe" carrier (Pardeike et al., 2009) 
Table 2. New formulations for lipid nanoparticles

\begin{tabular}{|c|c|c|c|c|}
\hline SOLID LIPIDS & $\begin{array}{l}\text { LIQUID } \\
\text { LIPIDS }\end{array}$ & EMULSIFIERS & DRUG & REFERENCES \\
\hline $\begin{array}{l}\text { Glyceryl behenate } \\
\text { (Compritol 888) }\end{array}$ & Oleic acid & $\begin{array}{c}\text { Tween } 80+\text { Dioctyl Sodium } \\
\text { Sulfoccinate }\end{array}$ & Quercitin & $\begin{array}{c}\text { (Bose \& } \\
\text { Michniak-Kohn, } \\
\text { 2013) }\end{array}$ \\
\hline Glycerol monostearate & $\begin{array}{l}\text { Medium chain } \\
\text { triglycerides }\end{array}$ & Lecithin + Poloxamer 188 & Sylibin & (Jia et al., 2010) \\
\hline $\begin{array}{l}\text { Compritol } 888 \text { ATO/ } \\
\text { Precirol ATO } 5\end{array}$ & & Polisorbate 80 & Paclitaxel & $\begin{array}{l}\text { (Videira et al., } \\
\text { 2013) }\end{array}$ \\
\hline Glycerol monostearate & & $\begin{array}{c}\text { Sodium Dodecil Sulphate }+ \\
\text { Bicephalous dianonic } \\
\text { surfactant }\end{array}$ & Ketoconazole & $\begin{array}{c}\text { (Kalhapure \& } \\
\text { Akamanchi,2013) }\end{array}$ \\
\hline $\begin{array}{l}\text { Compritol } 888 \text { ATO/ } \\
\text { Precirol ATO 5/ Imwitor } \\
\text { 900/ Cetyl palmitate }\end{array}$ & & Tween $80+$ Poloxamer 188 & Isotretinoin & $\begin{array}{l}\text { (Shiva et al., } \\
\text { 2012) }\end{array}$ \\
\hline $\begin{array}{c}\text { Glyceryl monostearate/ } \\
\text { Stearic acid }\end{array}$ & & Polyoxyl 40 Stearate & Tetracycline & (Xu et al., 2011) \\
\hline Stearic acid & $\begin{array}{l}\text { Miglyol } 812+ \\
\text { Castor oil }\end{array}$ & Tween 80 & Flurbiprofen & $\begin{array}{l}\text { (Gonzalez-Mira } \\
\text { et al., 2011) }\end{array}$ \\
\hline Compritol 888 ATO & & Poloxamer 188 & $\begin{array}{c}\text { Morphine } \\
\text { hydrochloride }\end{array}$ & $\begin{array}{c}\text { (Küchler et al., } \\
2010)\end{array}$ \\
\hline $\begin{array}{l}\text { Compritol } 888 \mathrm{ATO} / \\
\text { Imwitor } 900\end{array}$ & & Poloxamer $188+$ Tween 80 & Diazepam & $\begin{array}{l}\text { (Abdelbary \& } \\
\text { Fahmy, 2009) }\end{array}$ \\
\hline Stearic acid & & $\begin{array}{c}\text { Sodium Taurocholate+ } \\
\text { Epikuron } 200(92 \% \\
\text { phosphotidilcholine })\end{array}$ & Baclofen & $\begin{array}{l}\text { (Priano et al., } \\
\text { 2011) }\end{array}$ \\
\hline Stearylamine & & $\begin{array}{c}\text { Poloxamer 188 + Soya } \\
\text { Lecithin }\end{array}$ & Paclitaxel & $\begin{array}{l}\text { (Pandita et al., } \\
\text { 2011) }\end{array}$ \\
\hline Precirol ATO 5 & & Tween $80+$ DOTAP & $\begin{array}{l}\text { Dextran }+ \\
\text { Protamine }\end{array}$ & $\begin{array}{l}\text { (Delgado et al., } \\
2012 \text { ) }\end{array}$ \\
\hline Compritol 888 ATO & & Tween 80 & $\begin{array}{l}\text { Diclofenec } \\
\text { sodium }\end{array}$ & $\begin{array}{l}\text { (Spada et al., } \\
\text { 2012) }\end{array}$ \\
\hline Stearic acid & & Myrj59 + Lecithin & Pospho-sulindac & (Zhu et al., 2012) \\
\hline $\begin{array}{c}\text { Compritol } 888 \text { ATO + } \\
\text { Egg-phosphatidylcholine }\end{array}$ & & Poloxamer 188 & Sorafenib & $\begin{array}{l}\text { (Zhang et al., } \\
\text { 2012) }\end{array}$ \\
\hline Stearylamine & $\begin{array}{l}\text { Isopropyl } \\
\text { myristate }\end{array}$ & Soybean Lecithin & Tripterin & $\begin{array}{l}\text { (Chen et al., } \\
\text { 2012) }\end{array}$ \\
\hline $\begin{array}{c}\text { Compritol 888 ATO/ } \\
\text { Precirol ATO 5/ } \\
\text { Imwitor 900/ Beeswax/ } \\
\text { Stearic acid }\end{array}$ & & $\begin{array}{c}\text { Poloxamer } 188+\text { Sodium } \\
\text { Taurocholate }\end{array}$ & Gatifloxacin & $\begin{array}{l}\text { (Kalam et al., } \\
\text { 2012) }\end{array}$ \\
\hline Compritol 888 ATO & & Soya lecithin + Tween 80 & Triterpenediol & $\begin{array}{l}\text { (Bhushan et al., } \\
\text { 2013) }\end{array}$ \\
\hline $\begin{array}{l}\text { Docosahexaenoic acid }+ \\
\text { Compritol } 888 \text { ATO }\end{array}$ & & Tween 80 & Doxorubicin & $\begin{array}{l}\text { (Mussi et al., } \\
\text { 2013) }\end{array}$ \\
\hline Imwitor 900 & & Tween $80+$ Poloxamer 188 & Thymoquinone & $\begin{array}{l}\text { (Singh et al., } \\
2013 \text { ) }\end{array}$ \\
\hline
\end{tabular}


Table 2 shows novel formulations based on lipid nanoparticles, matching each drug with its solid lipid, the possible liquid lipid and the surfactant.

\subsection{Lipid Nanoparticles and Nervous System}

Efficacious non-invasive treatment of neurological diseases is frequently limited by the poor access of therapeutic agents into the central nervous system (CNS) (Wong et al., 2012). The larger amount of drugs and biotechnological agents are not able to permeate readily into brain parenchyma due to the presence of two anatomical and biochemical dynamic barriers: the BBB and blood cerebrospinal fluid barrier (BCSFB). Therefore, one of the most significant challenge for CNS drug development is the availability of effectual brain targeting technology (Patel et al., 2013). Recent advances in nanotechnology have provided promising solutions. Various nanocarriers ranging from the more established systems, such as polymeric nanoparticles, solid lipid nanoparticles, liposomes, micelles to the newer systems, e.g. dendrimers, nanogels, nanoemulsions and nanosuspensions have been studied for drug delivery into CNS. Many therapeutic agents can be effectively transported across several in vitro and in vivo BBB models by endocytosis and/or transcytosis, thus demonstrating early achievements for the management of CNS conditions e.g. brain tumors, HIV encephalopathy, Alzheimer's disease and acute ischemic stroke. Future development of CNS nanomedicines needs to focus on increasing their drug-trafficking performance and specificity for brain tissue using novel targeting carriers, improving their BBB permeability and reducing their neurotoxicity (Wong et al., 2012).

SLN have been reported as a promising anticancer drug delivery system to the brain, after intravenous injection, due to their ability to cross the barrier and deliver drugs to the brain (Martins et al., 2012). An improved brain accumulation of several compounds, especially anticancer drugs, was demonstrated when these drugs were delivered using SLN by administering them orally, intravenously and/or transdermally. Nanoparticles located in the external environment of a cell can interact with the plasma membrane, which can lead to the uptake of these nanoparticles by the cells through a process called "endocytosis" (Martins et al., 2012). If they cannot be internalized, the drug can still enter the cells after being released from the carriers, but it can also disperse to the surrounding normal tissues rather than be delivered mainly to the cancer cells. In fact, in vitro and in vivo studies reveal that the intracellular concentration of the drug is much higher when it is released from nanoparticles into the cytoplasm after internalization (Martins et al., 2012).

\subsection{Characterization of Lipid Nanoparticles}

The characterization of lipid nanoparticles is an important challenge due to their small size and complexity of the system. The pivotal parameters which need to be evaluated are particle size, size distribution kinetics (zeta potential, ZP), degree of crystallinity and lipid modification (polymorphism), coexistence of additional colloidal structures (micelles, liposome, super cooled, melts, drug nanoparticles), time scale of distribution process, drug entrapment efficiency, in vitro drug release and surface morphology (Waghmare, 2012).

Determination of particle size, ZP, PI and stability is essential for the development of new drug carrier systems. Particularly, particle size plays a key role in their in vitro behavior, in their in vivo distribution performance and in the success of site-specific drug delivery (Martins et al., 2011). It can be adjusted by varying process parameters such as homogenization pressure and cycle number, but is expected to depend on formulation composition such as surfactant and lipid concentration.

The assessment can be determined by photon correlation spectroscopy (PCS) also known as dynamic light scattering (DLS), by transmission electron microscopy (TEM), by scanning electron microscopy (SEM), by atomic force microscopy (AFM), by scanning tunneling microscopy (STM), by freeze fracture electron microscopy (FFEM) and by laser diffraction (LD) (Waghmare, 2012).

The lipid nanoparticles dispersions show a wide variability in macroscopic appearance, mean size and colloidal stability. Influence factors are e.g. the type and concentration of both lipid and surfactant components used. For instance, Martins et al. have proved that the most promising formulations obtained by their work, show a small mean size $(<200 \mathrm{~nm})$, a low PI $(<0.25)$, absence of particles in the several-micron range and a slightly negative $\mathrm{ZP}(>-12 \mathrm{mV})$. Differential scanning calorimetry (DSC) revealed that some of them represent super cooled liquids and they may be stable at room temperature for at least 1 year (Martins et al., 2011).

Very important is the route of administration considered and, in this regard, is crucial the choice of adequate physical-chemical and biological characteristics of the formulation. For example, in the case of lipid nanoparticles formulations for parenteral administration, surfactants generally recognized as safe should be preferred such as e.g. polysorbates and poloxamers. The main tasks of lipid nanoparticles systems for parenteral administration are good physical stability, protection of incorporated drugs from degradation, controlled drug 
release, good tolerability and site-specific targeting. Optimal colloidal stability may be reached by means of: a) small particle sizes in conjunction with a narrow (monomodal) size distribution and b) avoidance of particle aggregation and/or substantial particle growth during long-term storage (Martins et al., 2011).

\section{St. John's Wort and Nanotechnology}

Regarding the relationship between SJW and nanoparticles, very little is known in the literature and the larger amount of articles refers to the involvement of hypericin in the photodynamic therapy. Is commonly known that hypericin is a potent tool in vitro and in vivo for the treatment of cancer as photosensibilizer but, because of its hydrophobicity, the systemic administration is not possible. To overcome this limitation, Zeisser-Labouèbe et al. have introduced polymeric nanoparticles of polylactic acid (PLA) or polylactic-co-glycolic acid (PLGA) as drug delivery system for the treatment and detection of ovarian cancer (Zeisser-Labouebe et al., 2006). Hypericin loaded polymeric nanoparticles were produced with the following characteristics: 1) size in the 200-300 nm range, 2) negative zeta potential, 3) low residual PVAL and 4) drug loading from 0.03 to $0.15 \%(\mathrm{w} / \mathrm{w})$. Their results show that hypericin loaded PLA polymeric nanoparticles exhibit a higher photoactivity than free drug (Zeisser-Labouèbe et al., 2006).

Another way to use hypericin might be its formulation into SLN. This chance has attracted increasing attention as a potential drug delivery carrier. In fact, two hypericin loaded SLN formulations were prepared by Youssef et al. by using microemulsion-based technique (Youssef et al., 2012). Spectroscopic measurements of the photostability have showed that hypericin encapsulation into SLN improves its photostability, compared to free substance in $0.1 \%$ ethanolic solution. However, photocytotoxicity studies on cells have revealed an evident inhibition of the photodynamic efficacy of hypericin loaded SLN, compared to free hypericin (Youssef et al., 2012). Other several formulations of SJW were prepared by Hatanaka et al. including cyclodextrin inclusion (SJW-CD), solid dispersion (SJW-SD), dry-emulsion (SJW-DE) and nanoemulsion (SJW-NE) and their physicochemical properties were characterized with a focus on morphology, dissolution behavior, colloidal properties and dispersion stability in water (Hatanaka et al., 2011). Despite all the SJW formulations and extract itself exhibited good dissolution behavior in water, SJW extract and most formulations tended to cream, aggregate or flocculate after dispersion in distilled water. In contrast, there were no significant changes in appearance and particle size of the SJW-NE for at least a few weeks, suggesting that it is the most stable form as carrier of SJW. After oral administration of the SJW-NE formulation $(5.2 \mathrm{mg}$ hyperforin $/ \mathrm{kg}$ ) in mice, higher hyperforin exposure in plasma and the brain was observed with 2.8- and 1.3- fold increases, compared to SJW extract (Hatanaka et al., 2011). The NE formulation was prepared by using a mechanochemical method: the lipid phase, composed of SJW and medium chain triglyceride (MCT), and the aqueous phase, composed of glycerol, deionized water and emulsifying agents such as decaglyceryl monooleate and soybean lecithin, were heated to $80{ }^{\circ} \mathrm{C}$, separately. Then the two phases were mixed using an high-speed stirring at 9,000 rmp for $15 \mathrm{~min}$. In conclusion, their SJW-NE approach might be efficacious in improving the oral bioavailability and antinociceptive effect of SJW extract (Hatanaka et al., 2011).

Prakash et al. have investigated the effect of Hypericum perforatum gold nanoparticles (HPGNPs) protective role against restraint stress-induced behavioral in male albino mice, assuming that stress is associated with oxidative or free radical damage. SJW extract and HPGNPs have effectively improved the antioxidant enzyme activities such as superoxide dismutase, catalase, glutathione peroxidase and reduced glutathione in stress-treated animals. Both revealed a significant behavior and neuroprotective effect; however, the HPGNPs were more effective than the free extract. In their study, the leaves were air-dried at room temperature, finely powdered with auto-mix blender and stored in a deep freezer until the time of use. The methanolic extract was prepared using Soxhlet apparatus. Instead, for the biosynthesis of gold nanoparticles a solution of chloroauric acid was used. The extract supernatant was added to the chlorauric acid solution. The yellow-colored solution, which turns purple red slowly, indicates the formation of gold nanoparticles (Prakash et al., 2010).

\section{Conclusions and Future Perspectives}

Since lipid nanoparticles are able to enhance the chemical stability of compounds sensitive to light, oxidation and hydrolysis, and show a wide versatility as drug delivery system, it is expected their usefulness for the delivery of the extracts of SJW. The future prospect will be to develop and test SLN as colloidal carriers for hyperforin, highlighting the neuroprotective effect in neuronal cultures. The steps will include the pre-formulation solubility assays for appropriate selection of lipid matrices for SLN production, the production of optimized and long-term stable hyperforin loaded SLN formulations with high encapsulation efficiency and loading capacity, the formulation of SLN in semi-solid vehicles by testing the viscoelastic properties, the validation of characterization methodology and the establishment of optical SLN formulations in terms of 
physicochemical parameters and cyto/genotoxicity properties.

\section{Acknowledgments}

The authors wish to acknowledge Fundação para a Ciência e Tecnologia do Ministério da Ciência e Tecnologia, Fundo Comunitário do Programa FEDER/COMPETE, under the reference PTDC/SAU-FAR/113100/2009.

\section{Abbreviations}

\begin{tabular}{|c|c|}
\hline AFM & atomic force microscopy \\
\hline A-G/R injury & anoxic-glucopenia/reperfusion injury \\
\hline BBB & blood-brain barrier \\
\hline BCSFB & blood-cerebrospinal fluid barrier \\
\hline $\mathrm{CD}$ & cyclodextrin inclusion \\
\hline CNS & central nervous system \\
\hline CYP3A4 & cytochrome P-3A4 \\
\hline $\mathrm{DE}$ & dry-emulsion \\
\hline DLS & dynamic light scattering \\
\hline DSC & differential scanning calorimetry \\
\hline FDA & Food and Drug Administration \\
\hline FFEM & freeze fracture electron microscopy \\
\hline HIV & Human Immunodeficiency Virus \\
\hline HLB & hydrophile-lipophile balance \\
\hline $\mathrm{HPH}$ & high pressure homogenizer \\
\hline HPGNPs & hypericum perforatum gold nanoparticles \\
\hline iNOS & inducible nitric oxide synthase \\
\hline LD & laser diffraction \\
\hline $\mathrm{LN}$ & lipid nanoparticles \\
\hline MAO & monoamine oxidase \\
\hline MDD & major depressive disorder \\
\hline MTC & medium chain triglyceride \\
\hline NE & nanoemulsion \\
\hline NLC & nanostructured lipid carriers \\
\hline NMDA & N-metil-D-aspartato receptors \\
\hline NO & nitric oxide \\
\hline $\mathrm{OL}$ & oligodendocyte \\
\hline PCS & photon correlation spectroscopy \\
\hline $\mathrm{PGE}_{2}$ & prostaglandin $E_{2}$ \\
\hline PI & polydispersity index \\
\hline PKC & protein kinase $\mathrm{C}$ \\
\hline PLA & polylactic acid \\
\hline PLGA & polylactic-co-glycolic acid \\
\hline PVP & polyvinylpyrrolidone \\
\hline ROS & reactive oxygen species \\
\hline $\mathrm{SD}$ & solid dispersion \\
\hline SEM & scanning electron microscopy \\
\hline SJW & St. John's Wort \\
\hline
\end{tabular}




$\begin{array}{ll}\text { SLN } & \text { solid lipid nanoparticles } \\ \text { STM } & \text { scanning tunneling microscopy } \\ \text { TEM } & \text { transmission electron microscopy } \\ \text { TRPC6 } & \text { nonselective cationic channel permeable to } \mathrm{Ca}^{2+} \\ \text { ZP } & \text { zeta potential }\end{array}$

\section{References}

Abdelbary, G., \& Fahmy, R. H. (2009). Diazepam-Loaded Solid Lipid Nanoparticles: Design and Characterization. AAPS Pharm Sci Tech, 10(1), 211-219. http://dx.doi.org/10.1208/s12249-009-9197-2

Almeida, A. J., \& Souto, E. (2007). Solid lipid nanoparticles as a drug delivery system for peptides and proteins. Adv Drug Deliv Rev, 59(6), 478-490. http://dx.doi.org/10.1016/j.addr.2007.04.007

Bhushan, S. (2013). Enhanced Anticancer Potential of Encapsulated Solid Lipid Nanoparticles of TPD: A Novel Triterpenediol fromBoswellia serrata. Molecular Pharmaceutics, 10(1), $225-235$. http://dx.doi.org/10.1021/mp300385m

Bose, S., \& Michniak-Kohn, B. (2013). Preparation and characterization of lipid based nanosystems for topical delivery of quercetin. European Journal of Pharmaceutical Sciences, 48(3), $442-452$. http://dx.doi.org/10.1016/j.ejps.2012.12.005

Butterweck, V. (2003). Mechanism of action of St John's wort in depression: what is known? CNS Drugs, 17(8), 539-562. http://dx.doi.org/10.2165/00023210-200317080-00001

Caccia, S., \& Gobbi, M. (2009). St. John's wort components and the brain: uptake, concentrations reached and the mechanisms underlying pharmacological effects. Curr Drug Metab, 10(9), 1055-1065. http://dx.doi.org/10.2174/138920009790711878

Cervo, L. (2002). Role of hyperforin in the antidepressant-like activity of Hypericum perforatum extracts. Psychopharmacology (Berl), 164(4), 423-428. http://dx.doi.org/10.1007/s00213-002-1229-5

Chen, Y. (2012). Formulation, characterization, and evaluation of in vitro skin permeation and in vivo pharmacodynamics of surface-charged tripterine-loaded nanostructured lipid carriers. Int J Nanomedicine, 7 , 3023-3032.

Del Pozo-Rodriguez, A. (2013). Lipid nanoparticles as drug/gene delivery systems to the retina. J Ocul Pharmacol Ther, 29(2), 173-188. http://dx.doi.org/10.1089/jop.2012.0128

Delgado, D. (2012). Dextran-protamine-solid lipid nanoparticles as a non-viral vector for gene therapy: In vitro characterization and in vivo transfection after intravenous administration to mice. International Journal of Pharmaceutics, 425(1-2), 35-43. http://dx.doi.org/10.1016/j.ijpharm.2011.12.052

Fadel, M., Kassab, K., \& Youssef, T. (2010). Photodynamic efficacy of hypericin targeted by two delivery techniques to hepatocellular carcinoma cells. Lasers in Medical Science, 25(5), 675-683. http://dx.doi.org/10.1007/s10103-010-0787-8

Fangueiro, J. F., Andreani, T., Egea, M. A., Garcia, M. L., Souto, S. B., \& Souto, E. B. (2012). Experimental factorial design applied to mucoadhesive lipid nanoparticles via multiple emulsion process. Colloids Surf B Biointerfaces, 100, 84-89. http://dx.doi.org/10.1016/j.colsurfb.2012.04.014

Galeotti, N., \& Ghelardini, C. (2012). Reversal of NO-induced nociceptive hypersensitivity by St. John's wort and hypericin: NF-кB, CREB and STAT1 as molecular targets. Psychopharmacology.

Galeotti, N. ,Vivoli E., Bilia A. R., Vincieri F. F., \& Ghelardini, C. (2010). St. John's Wort reduces neuropathic pain through a hypericin-mediated inhibition of the protein kinase $\mathrm{C} \gamma$ and $\varepsilon$ activity. Biochemical Pharmacology, 79, 1327-1336. http://dx.doi.org/10.1016/j.bcp.2009.12.016.

Gibon, J., Richaud, P., \& Bouron, A. (2011). Hyperforin changes the zinc-storage capacities of brain cells. Neuropharmacology, 61(8), 1321-1326. http://dx.doi.org/10.1016/j.neuropharm.2011.08.002

Gonzalez-Mira, E., Egea M. A., Souto E. B., Calpena A. C., \& García, M. L. (2011). Optimizing flurbiprofen-loaded NLC by central composite factorial design for ocular delivery. Nanotechnology, 22(4), 045101. http://dx.doi.org/10.1088/0957-4484/22/4/045101

Griffith, T. N., Varela-Nallar, L., Dinamarca, M. C., \& Inestrosa, N. C. (2010). Neurobiological effects of 
Hyperforin and its potential in Alzheimer's disease therapy. Curr Med Chem, 17(5), 391-406. http://dx.doi.org/10.2174/092986710790226156

Gröning, R., Breitkreutz, J., \& Müller, R. S. (2003). Physico-chemical interactions between extracts of Hypericum perforatum L. and drugs. European Journal of Pharmaceutics and Biopharmaceutics, 56(2), 231-236. http://dx.doi.org/10.1016/s0939-6411(03)00094-8

Hadjur, C., Richard, M. J., Parat, M. O., Jardon, P., \& Favier, A. (1996). Photodynamic effects of hypericin on lipid peroxidation and antioxidant status in melanoma cells. Photochem Photobiol, 64(2), 375-381. http://dx.doi.org/10.1111/j.1751-1097.1996.tb02474.x

Hatanaka, J., Shinme, Y., Kuriyama, K., Uchida, A., Kou, K., Uchida, S., Yamada, S., \& Onoue, S. (2011). In vitro and in vivo Characterization of New Formulations of St. John's Wort Extract with Improved Pharmacokinetics and Anti-nociceptive Effect. Drug Metabolism and Pharmacokinetics, 26(6), 551-558. http://dx.doi.org/10.2133/dmpk.DMPK-11-RG-041

Huntosova, V., Nadova, Z., Dzurova, L., Jakusova, V., Sureau, F., \& Miskovsky, P. (2012). Cell death response of U87 glioma cells on hypericin photoactivation is mediated by dynamics of hypericin subcellular distribution and its aggregation in cellular organelles. Photochemical \& Photobiological Sciences, 11(9), 1428. http://dx.doi.org/10.1039/c2pp05409d

Isacchi, B., Galeotti, N., Bergonzi, M. C., Ghelardini, C., Bilia, A. R., \& Vincieri, F. F. (2009). Pharmacologicalin vivotest to evaluate the bioavailability of some St John's Wort innovative oral preparations. Phytotherapy Research, 23(2), 197-205. http://dx.doi.org/10.1002/ptr.2586

Jia, L.-J., Zhang, D.-R., Li, Z.-Y., Feng, F.-F., Wang, Y.-C., Dai, W.-T., Duan, C.-X., \& Zhang, Q. (2010). Preparation and characterization of silybin-loaded nanostructured lipid carriers. Drug Delivery, 17(1), 11-18. http://dx.doi.org/10.3109/10717540903431586

Kah, J. C., Lau, W. K., Tan, P. H., Sheppard, C. J., \& Olivo, M. (2008). Endoscopic image analysis of photosensitizer fluorescence as a promising noninvasive approach for pathological grading of bladder cancer in situ. J Biomed Opt, 13(5), 054022. http://dx.doi.org/10.1117/1.2981827

Kalam, M. A., Sultana, Y., Ali, A., Aqil, M., Mishra, A. K., Aljuffali, I. A., \& Alshamsan, A. (2012). Part I: Development and optimization of solid-lipid nanoparticles using Box-Behnken statistical design for ocular delivery of gatifloxacin. Journal of Biomedical Materials Research Part A, n/a-n/a. http://dx.doi.org/10.1002/jbm.a.34453

Kalhapure, R. S., \& Akamanchi, K. G. (2013). A novel biocompatible bicephalous dianionic surfactant from oleic acid for solid lipid nanoparticles. Colloids and Surfaces B: Biointerfaces, 105, 215-222. http://dx.doi.org/10.1016/j.colsurfb.2013.01.011

Khan, A.-u., Gilani A.-H., \& Najeeb, ur R. (2011). Pharmacological studies onHypericum perforatumfractions and constituents. Pharmaceutical Biology, 49(1), 46-56. http://dx.doi.org/10.3109/13880209.2010.494307

Kim, D.-S., Ryu, H. J., Kim, J.-E., \& Kang, T.-C. (2012). The Reverse Roles of Transient Receptor Potential Canonical Channel-3 and -6 in Neuronal Death Following Pilocarpine-Induced Status Epilepticus. Cellular and Molecular Neurobiology, 33(1), 99-109. http://dx.doi.org/10.1007/s10571-012-9875-6

Klemow, K. M., Bartlow, A., Crawford, J., Kocher, N., Shah, J., \& Ritsick, M. (2011). Medical Attributes of St. John's Wort (Hypericum perforatum). http://dx.doi.org/NBK92750

Kraus, B. ,Wolff H. ,Elstner E. F. \& Heilmann J. (2010). Hyperforin is a modulator of inducible nitric oxide synthase and phagocytosis in microglia and macrophages. Naunyn-Schmiedeberg's Archives of Pharmacology, 381(6), 541-553. http://dx.doi.org/10.1007/s00210-010-0512-y

Küchler, S., Nadine, B. W., Sarah, H., Günther, W., Jürgen, H., Momin, M. Y., Christoph, S., \& Monika, S. K. (2010). 3D-Wound healing model: Influence of morphine and solid lipid nanoparticles. Journal of Biotechnology, 148(1), 24-30. http://dx.doi.org/10.1016/j.jbiotec.2010.01.001

Kumar, V., Mdzinarishvili, A., Kiewert, C., Abbruscato, T., Bickel, U., van der Schyf, C. J., \& Klein, J. (2006). NMDA receptor-antagonistic properties of hyperforin, a constituent of St. John's Wort. J Pharmacol Sci, 102(1), 47-54. http://dx.doi.org/10.1254/jphs.FP0060378

Leuner, K., Li, W., Amaral, M. D., Rudolph, S., Calfa, G., Schuwald, A. M., ... Pozzo-Miller, L. (2013). Hyperforin modulates dendritic spine morphology in hippocampal pyramidal neurons by activating $\mathrm{Ca}^{2+}$-permeable TRPC6 channels. Hippocampus, 23(1), 40-52. http://dx.doi.org/10.1002/hipo.22052 
Lu, W. D., \& Atkins, W. M. (2004). A novel antioxidant role for ligandin behavior of glutathione S-transferases: attenuation of the photodynamic effects of hypericin. Biochemistry, 43(40), 12761-12769. http://dx.doi.org/10.1021/bi049217m

Martins, S., Costa-Lima, S., Carneiro, T., Cordeiro-da-Silva, A., Souto, E. B., \& Ferreira, D. C. (2012). Solid lipid nanoparticles as intracellular drug transporters: An investigation of the uptake mechanism and pathway. $\begin{array}{llll}\text { International Journal of 216-227. } & \text { Pharmaceutics, }\end{array}$ http://dx.doi.org/10.1016/j.jpharm.2012.03.032

Martins, S., Tho, I., Ferreira, D. C., Souto, E. B., \& Brandl, M. (2011). Physicochemical properties of lipid nanoparticles: Effect of lipid and surfactant composition. Drug Development and Industrial Pharmacy, 37(7), 815-824. http://dx.doi.org/10.3109/03639045.2010.545414

Meinke, M. C., Schanzer, S., Haag, S. F., Casetti, F., Müller, M. L., Wölfle, U., ... Schempp, C. M. (2012). In vivo photoprotective and anti-inflammatory effect of hyperforin is associated with high antioxidant activity in vitro and ex vivo. European Journal of Pharmaceutics and Biopharmaceutics, 81(2), 346-350. http://dx.doi.org/10.1016/j.ejpb.2012.03.002

Mennini, T., \& Gobbi, M. (2004). The antidepressant mechanism of Hypericum perforatum. Life Sciences, 75(9), 1021-1027. http://dx.doi.org/10.1016/j.lfs.2004.04.005

Muller, R. H., Mader, K., \& Gohla, S. (2000). Solid lipid nanoparticles (SLN) for controlled drug delivery - a review of the state of the art. Eur $J$ Pharm Biopharm, 50(1), 161-177. http://dx.doi.org/S0939-6411(00)00087-4

Müller, R. S., Breitkreutz, J., \& Gröning, R. (2004). Interactions between aqueousHypericum perforatum extracts and drugs:in vitro studies. Phytotherapy Research, 18(12), 1019-1023. http://dx.doi.org/10.1002/ptr.1601

Mussi, S. V., Silva R. C., Oliveira M. C. D., Lucci C. M., Azevedo, R. B. D., \& Ferreira L. A. M. (2013). New approach to improve encapsulation and antitumor activity of doxorubicin loaded in solid lipid nanoparticles. $\begin{array}{lllll}\text { European Journal of } & \text { Pharmaceutical }\end{array}$ http://dx.doi.org/10.1016/j.ejps.2012.10.025

Nahrstedt, A., \& Butterweck, V. (2010). Lessons learned from herbal medicinal products: the example of St. John's Wort (perpendicular). J Nat Pro , 73(5), 1015-1021. http://dx.doi.org/10.1021/np1000329

Onoue, S., Seto, Y., Ochi, M., Inoue, R., Ito, H.,Hatano, T., \& Yamada, S. (2011). In vitro photochemical and phototoxicological characterization of major constituents in St. John's Wort (Hypericum perforatum) extracts. Phytochemistry, 72(14-15), 1814-1820. http://dx.doi.org/10.1016/j.phytochem.2011.06.011

Ott, M., Huls, M., Cornelius, M. G., \& Fricker, G. (2010). St. John's Wort Constituents Modulate P-glycoprotein Transport Activity at the Blood-Brain Barrier. Pharmaceutical Research, 27(5), 811-822. http://dx.doi.org/10.1007/s11095-010-0074-1

Pandita, D., Ahuja, A., Lather, V., Benjamin, B., Dutta, T., Velpandian, T., \& Khar, R. K. (2011). Development of Lipid-Based Nanoparticles for Enhancing the Oral Bioavailability of Paclitaxel. AAPS PharmSciTech, 12(2), 712-722. http://dx.doi.org/10.1208/s12249-011-9636-8

Pardeike, J., Hommoss, A., \& Müller, R. H. (2009). Lipid nanoparticles (SLN, NLC) in cosmetic and pharmaceutical dermal products. International Journal of Pharmaceutics, 366(1-2), 170-184. http://dx.doi.org/10.1016/j.ijpharm.2008.10.003

Patel, M., Souto, E. B., \& Singh, K. K. (2013). Advances in brain drug targeting and delivery: limitations and challenges of solid lipid nanoparticles. Expert Opin Drug Deliv. http://dx.doi.org/10.1517/17425247.2013.784742

Prakash, D. J., Arulkumar, S., \& Sabesan, M. (2010). Effect of nanohypericum (Hypericum perforatum gold nanoparticles) treatment on restraint stressinduced behavioral and biochemical alteration in male albino mice. Pharmacognosy Res, 2(6), 330-334. http://dx.doi.org/10.4103/0974-8490.75450

Priano, L., Zara, G. P., El-Assawy, N., Cattaldo, S., Muntoni, E., Milano, E., ... Mauro, A. (2011). Baclofen-loaded solid lipid nanoparticles: Preparation, electrophysiological assessment of efficacy, pharmacokinetic and tissue distribution in rats after intraperitoneal administration. European Journal of Pharmaceutics and Biopharmaceutics, 79(1), 135-141. http://dx.doi.org/10.1016/j.ejpb.2011.02.009

Ritz, R., Muller, M., Dietz, K., Duffner, F., Bornemann, A., Roser, F., \& Tatagiba, M. (2008). Hypericin uptake: 
a prognostic marker for survival in high-grade glioma. $J$ Clin Neurosci, 15(7), 778-783. http://dx.doi.org/10.1016/j.jocn.2007.03.022

Saddiqe, Z., Naeem, I., \& Maimoona, A. (2010). A review of the antibacterial activity of Hypericum perforatum L. Journal of Ethnopharmacology, 131(3), 511-521. http://dx.doi.org/10.1016/j.jep.2010.07.034

Severino, P., Andreani, T., Macedo, A. S., Fangueiro, J. F., Santana, M. H. A., Silva, A. M., \& Souto, E. B. (2012). Current State-of-Art and New Trends on Lipid Nanoparticles (SLN and NLC) for Oral Drug Delivery. Journal of Drug Delivery, 2012, 1-10. http://dx.doi.org/10.1155/2012/750891

Severino, P., Fangueiro, J. F., Ferreira, S. V., Basso, R., Chaud, M. V., Santana, M. H., ... Souto, E. B. (2013). Nanoemulsions and nanoparticles for non-melanoma skin cancer: effects of lipid materials. Clin Transl Oncol. http://dx.doi.org/10.1007/s12094-012-0982-0

Shiva, G., Somaye, M., \& Reza, J. M. (2012). Improved photostability, reduced skin permeation and irritation of isotretinoin by solid lipid nanoparticles / Povećana fotostabilnost, smanjena permeacija i iritacija izotretinoina iz kruto-tekućih nanočestica. Acta Pharmaceutica, 62(4). http://dx.doi.org/10.2478/v10007-012-0032-z

Silva, B., Oliveira, P. J., Dias, A., \& Malva, J. O. (2008). Quercetin, kaempferol and biapigenin from Hypericum perforatum are neuroprotective against excitotoxic insults. Neurotox Res, 13(3-4), 265-279. http://dx.doi.org/http://dx.doi.org/10.1007/BF03033510

Singh, A., Ahmad, I., Akhter, S., Jain, G. K., Iqbal, Z., Talegaonkar, S., \& Ahmad, F. J. (2013). Nanocarrier based formulation of Thymoquinone improves oral delivery: Stability assessment, in vitro and in vivo $\begin{array}{llllll}\text { studies. } \quad \text { Colloids and } & \text { Burfaces }\end{array}$ http://dx.doi.org/10.1016/j.colsurfb.2012.08.038

Souto, E. B., Doktorovova, S., Gonzalez-Mira, E., Egea, M. A., \& Garcia, M. L. (2010). Feasibility of lipid nanoparticles for ocular delivery of anti-inflammatory drugs. Curr Eye Res, 35(7), 537-552. http://dx.doi.org/10.3109/02713681003760168

Souto, E. B., \& Muller, R. H. (2008). Cosmetic features and applications of lipid nanoparticles (SLN, NLC). Int J Cosmet Sci, 30(3), 157-165. http://dx.doi.org/10.1111/j.1468-2494.2008.00433.x

Souto, E. B., \& Muller, R. H. (2010). Lipid nanoparticles: effect on bioavailability and pharmacokinetic changes. Handb Exp Pharmacol, 197, 115-141. http://dx.doi.org/10.1007/978-3-642-00477-3_4

Spada, G., Gavini, E., Cossu, M., Rassu, G., \& Giunchedi, P. (2012). Solid lipid nanoparticles with and without hydroxypropyl- $\beta$-cyclodextrin: a comparative study of nanoparticles designed for colonic drug delivery. Nanotechnology, 23(9), 095101. http://dx.doi.org/10.1088/0957-4484/23/9/095101

Tu, P., Gibon, J., \& Bouron, A. (2010). The TRPC6 channel activator hyperforin induces the release of zinc and $\begin{array}{lllll}\text { calcium from } & \text { mitochondria. } J \text { Neurochem, }\end{array}$ http://dx.doi.org/10.1111/j.1471-4159.2009.06446.x

Uzdensky, A. B., Bragin, D. E., Kolosov, M. S., Kubin, A., Loew, H. G., \& Moan, J. (2003). Photodynamic effect of hypericin and a water-soluble derivative on isolated crayfish neuron and surrounding glial cells. Journal of Photochemistry and Photobiology B: Biology, 72(1-3), 27-33. http://dx.doi.org/10.1016/j.jphotobiol.2003.08.008

Valeri, A., Capasso, R., Valoti, M., \& Pessina, F. (2012). Effects of St John's wort and its active constituents, hypericin and hyperforin, on isolated rat urinary bladder. Journal of Pharmacy and Pharmacology, 64(12), 1770-1776. http://dx.doi.org/10.1111/j.2042-7158.2012.01556.x

Verotta, L. (2003). Hypericum perforatum, a source of neuroactive lead structures. Curr Top Med Chem, 3(2), 187-201. http://dx.doi.org/http://dx.doi.org/10.2174/1568026033392589

Videira, M. A., Arranja, A. G., \& Gouveia, L. F. (2013). Experimental design towards an optimal lipid nanosystem: A new opportunity for paclitaxel-based therapeutics. European Journal of Pharmaceutical Sciences. http://dx.doi.org/10.1016/j.ejps.2013.03.005

Waghmare, A. S. (2012). Solid Lipid Nanoparticles: a Promising Drug Delivery System. International Research Journal of Pharmacy, 3(4), 100-107.

Wang, Y., Shi, X., \& Qi, Z. (2010). Hypericin prolongs action potential duration in hippocampal neurons by $\begin{array}{llllll}\text { acting on } \mathrm{K}^{+} \text {channels. } \mathrm{Br} J \text { Pharmacol, } & 159(7), & 1402-1407 .\end{array}$ http://dx.doi.org/10.1111/j.1476-5381.2009.00513.x 
Wang, Y., Zhang, Y., He, J., Zhang, H., Xiao, L., Nazarali, A., ... Li, X. M. (2011). Hyperforin promotes mitochondrial function and development of oligodendrocytes. Journal of Neurochemistry, 119(3), 555-568. http://dx.doi.org/10.1111/j.1471-4159.2011.07433.x

Wang, Z. L., \& Wu, W. (2012). Nanotechnology-enabled energy harvesting for self-powered micro-/nanosystems. Angew Chem Int Ed Engl, 51(47), 11700-11721. http://dx.doi.org/10.1002/anie.201201656

Werz, O., Sautebin, L., Northoff, H., Verotta, L., Dehm, F., Bauer, J., ... Koeberle, A. (2011). Hyperforin, an Anti-Inflammatory Constituent from St. John's Wort, Inhibits Microsomal Prostaglandin E2 Synthase-1 and Suppresses Prostaglandin E2 Formation in vivo. Frontiers in Pharmacology, 2. http://dx.doi.org/10.3389/fphar.2011.00007

Weyhers, H., Ehlers, S., Hahn, H., Souto, E. B., \& Muller, R. H. (2006). Solid lipid nanoparticles (SLN)-effects of lipid composition on in vitro degradation and in vivo toxicity. Pharmazie, 61(6), 539-544.

Wong, H. L.,Wu X. Y., \& Bendayan, R. (2012). Nanotechnological advances for the delivery of CNS $\begin{array}{llll}\text { therapeutics. Advanced Drug Delivery } & \text { Reviews, }\end{array}$ http://dx.doi.org/10.1016/j.addr.2011.10.007

Xia, Q., Saupe, A., Muller, R. H., \& Souto, E. B. (2007). Nanostructured lipid carriers as novel carrier for $\begin{array}{lllll}\text { sunscreen formulations. Int } J \text { Cosmet } & \text { Sci, } & \text { 29(6), } & \text { 473-482. }\end{array}$ http://dx.doi.org/10.1111/j.1468-2494.2007.00410.x

Xu, X. M., Wang, Y. S., Chen, R. Y., Feng, C. L., Yao, F., Tong, S. S.,... Yu, J. N. (2011). Formulation and pharmacokinetic evaluation of tetracycline-loaded solid lipid nanoparticles for subcutaneous injection in mice. Chem Pharm Bull (Tokyo), 59(2), 260-265. http://dx.doi.org/JST.JSTAGE/cpb/59.260

Youssef, T., Fadel, M., Fahmy, R., \& Kassab, K. (2012). Evaluation of hypericin-loaded solid lipid nanoparticles: physicochemical properties, photostability and phototoxicity. Pharm Dev Technol, 17(2), 177-186. http://dx.doi.org/10.3109/10837450.2010.529148

Zeisser-Labouèbe, M., Lange, N., Gurny, R., \& Delie, F. (2006). Hypericin-loaded nanoparticles for the photodynamic treatment of ovarian cancer. International Journal of Pharmaceutics, 326(1-2), 174-181. http://dx.doi.org/10.1016/j.ijpharm.2006.07.012

Zhang, H., Zhang, F., \& Yan, S. (2012). Preparation, in vitro release, and pharmacokinetics in rabbits of lyophilized injection of sorafenib solid lipid nanoparticles. International Journal of Nanomedicine, 2901. http://dx.doi.org/10.2147/ijn.s32415

Zhu, R., Cheng, K.-W., Mackenzie, G., Huang, L., Sun, Y., Xie, G., ... Rigas, B. (2012). Phospho-Sulindac (OXT-328) Inhibits the Growth of Human Lung Cancer Xenografts in Mice: Enhanced Efficacy and Mitochondria Targeting by its Formulation in Solid Lipid Nanoparticles. Pharmaceutical Research, 29(11), 3090-3101. http://dx.doi.org/10.1007/s11095-012-0801-x

\section{Copyrights}

Copyright for this article is retained by the author(s), with first publication rights granted to the journal.

This is an open-access article distributed under the terms and conditions of the Creative Commons Attribution license (http://creativecommons.org/licenses/by/3.0/). 